\title{
DIGITALIZACIJA NEGATIVOV NA STEKLIH ODDELKA ZA GEOGRAFIJO
}

Fotografija kot vizualen in dokumentaren zgodovinski vir ima pomembno mesto tudi v geografskem raziskovanju. Kot popolna odslikava resničnosti so fotografije pomembno dopolnilo pisnih virov in tisti del kulturne dediščine, ki ima znanstveno, kulturnozgodovinsko in estetsko vrednost. Lahko se pojavljajo kot slikovno gradivo v knjigah ali preko njih proučujemo zgodovino, pojave, pokrajino in ljudi v preteklosti. Pomembne so zaradi svoje dokumentarne vrednosti, saj poleg glavnega motiva lahko opazujemo tudi razne druge detajle, ki so pomembni za proučevanje (Suhadolnik, 2001). Tako kot fotografije imajo posebno vrednost tudi fotografske tehnike, ki so se in se uporabljajo pri fotografiranju.

Negativi na steklu so del fotografske tehnike, ki se je uporabljala od druge polovice sedemdesetih let 19. stoletja. Pomenili so revolucijo v razmahu fotografije. Prednost fotografske tehnike z uporabo stekel je bila, da so se steklene plošče lahko uporabljale suhe in jih ni bilo treba sproti pripravljati v temnicah na terenu. Steklo ima ravno površino, bilo je cenejše, lažje od kovine in zato primernejše za izdelovanje negativov. Fotografi niso bili več vezani na atelje, pogosteje so se odpravili na teren in lahko so posneli več fotografij naenkrat. To so storili z velikoformatnimi kamerami na film v zvitku, ki so ga nato razvili na vsak negativ posebej in ga prenesli na stekleno ploščo. Časi osvetlitve so bili krajši od ene sekunde. V želji po ostrini pa so fotografi še vedno morali uporabljati fotografska stojala. Danes so negativi na steklu izjemna redkost in zato dragocen del osebne ter nacionalne in kulturne dediščine (Farič, 2017).

Starejše fotografije so imele navedbo fotografa, kasneje pa se je ta praksa opuščala, kar otežuje njihovo identifikacijo. Tako je bilo tudi s fotografskim arhivom Oddelka za geografijo, za katerega ni točno znano, kdo ga je daroval Oddelku. Z dokaj veliko verjetnostjo predvidevamo, da je fotografije posnel Anton Melik s sodelavci in da so bili negativi njegova last. Zbirka obsega 454 negativov na steklu. Do devetdesetih let se je hranila v kartografskem laboratoriju, ob preureditvi le-tega pa so jo preselili v kartografsko zbirko knjižnice, kjer je sedaj shranjena v omari v posebnih škatlah. Negativi so zloženi v ležečem položaju po zaporedju, ki nima vsebinske povezave. Vloženi so v posebne žepke iz prosojnega papirja, na katerem so podatki o številki negativa, točnem datumu ali letu posnetka in vsebini posnetka. Negativi so dveh velikosti, in sicer $12 \mathrm{x} 9 \mathrm{~cm}$ in $15 \mathrm{x}$ $10 \mathrm{~cm}$, debelina stekla je $1 \mathrm{~mm}$.

Kljub temu da so negativi na steklu trajen in kakovosten fotografski zapis in da so shranjeni v pogojih z ustrezno relativno vlago in temperaturo, se tako kot drugi fizični analogni mediji starajo in izgubljajo kakovost. Fotografski postopki in tehnologija so napredovali, zato njihova ponovna uporaba ni enostavna in zaradi zaščite pred poškodbami nepriporočljiva. Digitalizacija analognega gradiva danes velja za eno najprimernejših in najpomembnejših metod ohranjanja slikovne kulturne dediščine (Dobravec, 2015). Vsebina se na ta način ohrani, omogočena je uporaba širši javnosti, izvirniki pa so zaščiteni 
pred negativnimi dejavniki uporabe. Zaradi vseh teh razlogov smo se v knjižnici odločili, da bomo zbirko negativov na steklu digitalizirali.

Digitalizacija negativov na steklu je potekala leta 2017. Negative smo skenirali z optičnim bralnikom, ki je s posebnim ozadjem omogočal primerno osvetlitev, tako da smo dobili čim bolj kakovostno fotografijo. Nekaj negativov smo digitalizirali s pomočjo fotoaparata. Dobili smo 413 datotek v formatu JPEG. Enainštirideset negativov je bilo že tako poškodovanih, da ni bilo možno razbrati vsebine, zato jih nismo digitalizirali. Datoteke smo shranjevali na knjižnični strežnik. Hkrati smo pripravljali metapodatkovne opise, ki so vsebovali podatke o naslovu (vsebini fotografije), datumu ali letnici nastanka fotografije, geografskih ključnih besedah, povzetih po vsebinskih predmetnih oznakah, ki jih uporablja knjižnica za katalogizacijo gradiva, in oznako področja, ki ga uporablja portal Kamra. Fotografije smo nato uredili po tematskih sklopih. Zbirka je bila 30. 12. 2017 objavljena na portalu Kamra. To je slovenski regijski portal, na katerem se objavljajo digitalizirane vsebine s področja domoznanstva, ki jih hranijo knjižnice in lokalne kulturne ustanove. Za Kamro smo se odločiti, ker so skrbniki izvedli postopek objave in ker sta zagotovljena vmesnik in hramba datotek na rezervni lokaciji. Zbirka je tako dostopna tudi preko Europeane - evropske digitalne knjižnice.

Negativi so na Kamri objavljeni znotraj trinajstih tematskih sklopov, in sicer Alpske pokrajine, Avstrijska Koroška, Dinarskokraške pokrajine, Ekskurzije študentov Oddelka za geografijo, Geomorfološke oblike, Kozolci, Kras, Ljubljansko barje, Naselja, Planine, Pomurje, Predalpske pokrajine in Stavbna dediščina. Vsak sklop ima opis, fotografije pa poleg naslova še kategorijo, oznako lokacije na podlagi najbližje poštne številke in podatek o času nastanka.

Med motivi prevladujejo fotografije pokrajine, veliko je fotografij stavbne dediščine (kmečke hiše, gospodarska poslopja, planinski stanovi, miljni kamni). V sklopu Kras najdemo fotografije kraških jam, izvirov kraških rek in kraških oblik (žlebiči, ponori), med geomorfološkimi oblikami pa predvsem rečne terase, morene in krnice. V sklopu Ljubljansko barje so zanimive fotografije, ki prikazujejo rezanje šote in gradnjo hiše na Barju. Zelo obsežen je sklop fotografij, ki prikazujejo kozolce iz različnih pokrajin Slovenije, med njimi najdemo dvojne stegnjene kozolce, prislonjene kozolce, kozolce na kozla itd. Fotografije imajo tudi veliko etnološko vrednost, ker so na njih poleg glavnega motiva dokumentirani ljudje, ko bodisi pozirajo fotografu bodisi so v objektiv ujeti pri raznih opravilih, ob praznovanjih itd.

Ugotavljamo, da je bila odločitev za digitalizacijo negativov na steklu prava, saj smo s tem zaščitili negative pred neprimerno uporabo, ohranili njihovo vsebino in širši javnosti omogočili vpogled v zbirko. Brez ustreznih aparatov tega gradiva namreč ni več mogoče pregledovati. Zbirka je z objavo doživela pozitiven odziv med uporabniki, kar dokazuje statistika ogledov na spletni strani Kamre. 


\section{Viri}

Arhiv negativov na steklih Oddelka za geografijo. Kamra. URL: https://www.kamra.si/ digitalne-zbirke/item/zbirka-negativov-oddelka-za-geografijo.html (citirano 20. 11. 2018).

Dobravec, J., 2015. Katalogizacija in digitalizacija arhiva fotografskih negativov na steklenih ploščah avtorja Janka Ravnika. Arhivi, 38, 2, str. 325-342. URL: http://www. arhivsko-drustvo.si/Arhivi/Arhivi_2015-2.pdf (citirano 15. 11. 2018).

Farič, B., 2017. Tempora mutantur: vedute Ptuja na negativih na steklu in skozi objektiv Borisa Fariča. Ptuj, Pokrajinski muzej Ptuj - Ormož; Salon umetnosti Ptuj, 15 str.

Hedgecoe, J., 1981. Vse o fotografiji. Ljubljana, DZS, 255 str.

Miklič Cvek, L., 2018. Negativi na steklu Oddelka za geografijo. Geografska širina, maj, str. 4. URL: http://geo.ff.uni-lj.si/sites/geo.ff.uni-lj.si/files/DatotekeVsebin/Stoletnica/geo_sirina_01_maj18.pdf(citirano 20.11.2018).

Suhadolnik, J., 2001. Fotografija - arhivsko gradivo in arhivske fototeke. Osnove in načini urejanja, popisovanja in strokovne obdelave. Arhivi, 24, 1, str. 59-68. URL: http:// www.arhivsko-drustvo.si/Arhivi/Arhivi_2001-1.pdf (citirano 15. 11. 2018).

Tamar na Ribenski planini (Jelovica).

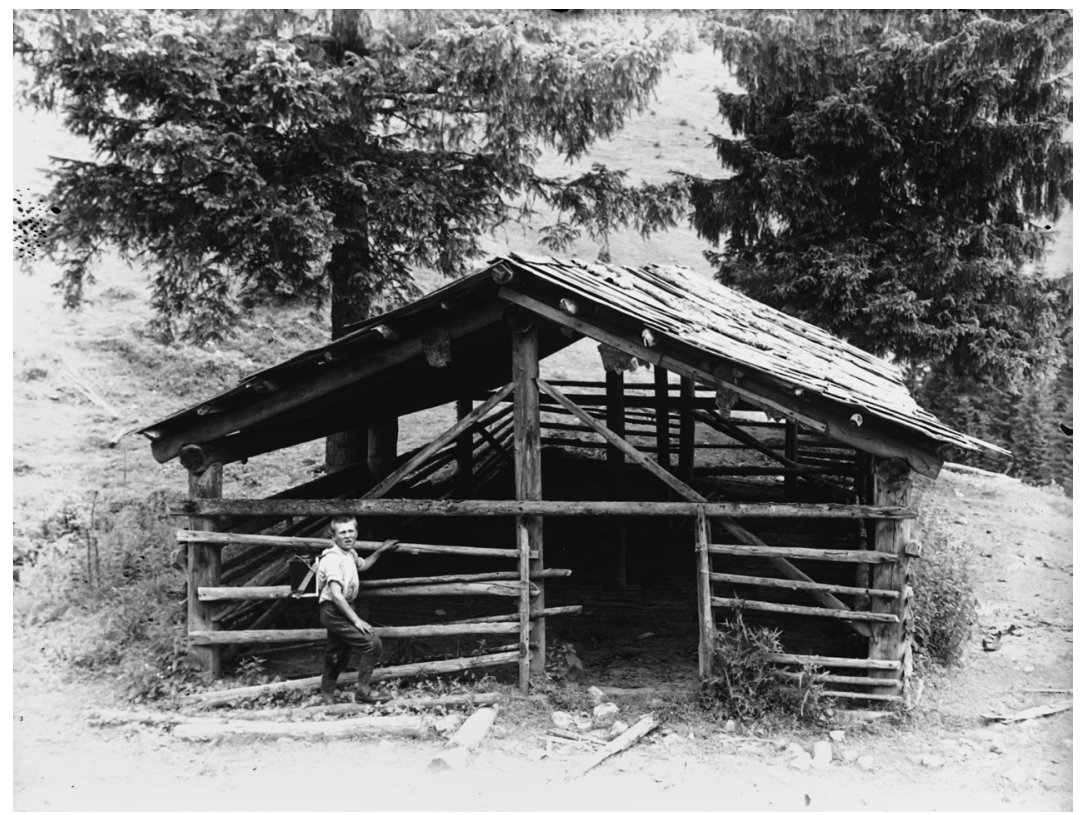




\section{Šota na Ljubljanskem barju.}

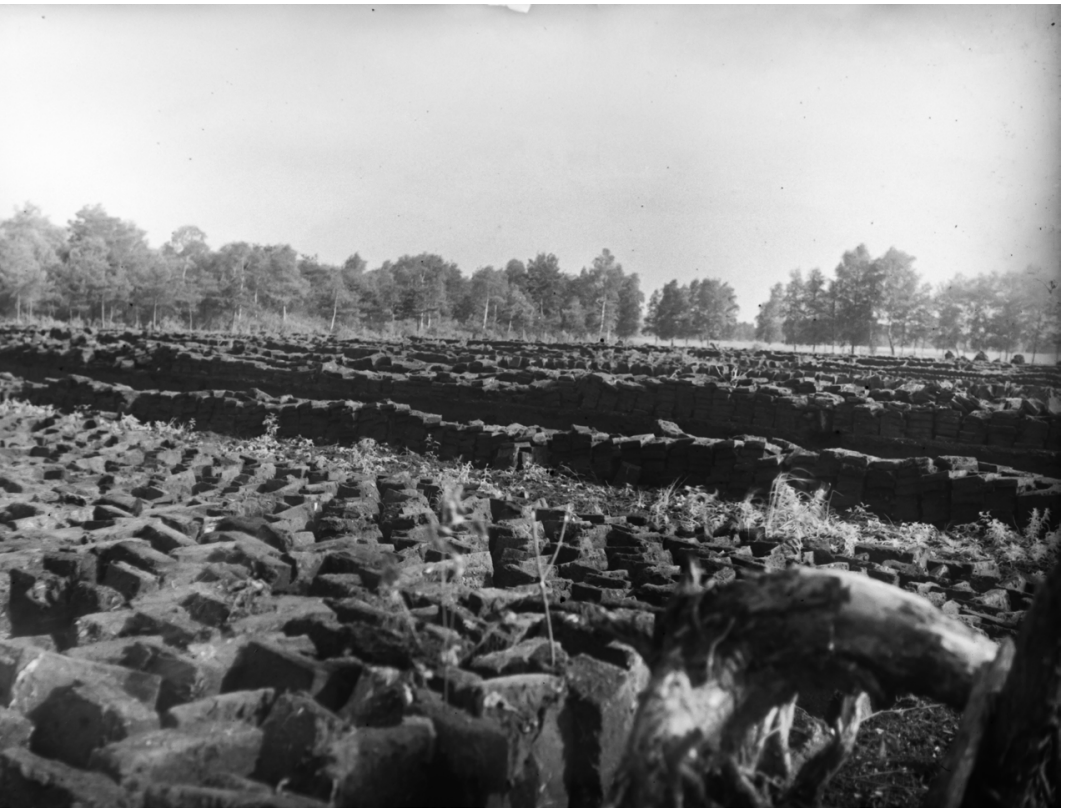

Hiša pri Markotcu (Koprivnik v Bohinju).

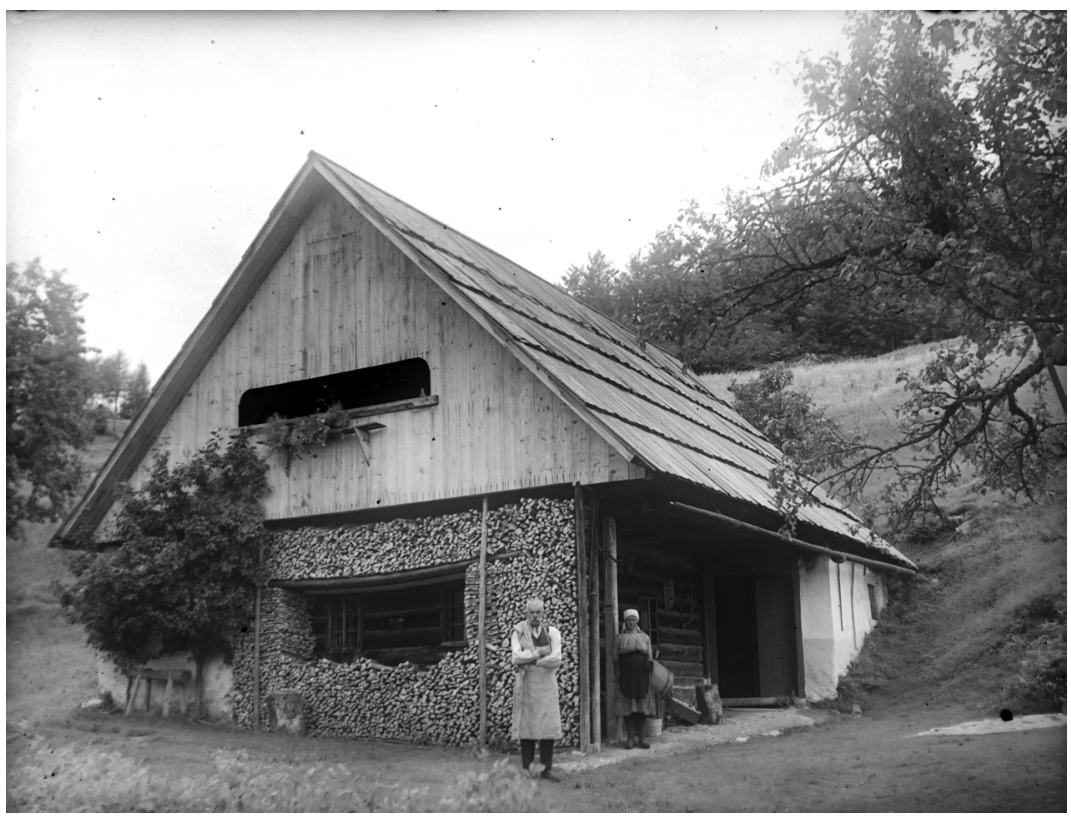


Vas Šikole pri Pragerskem.

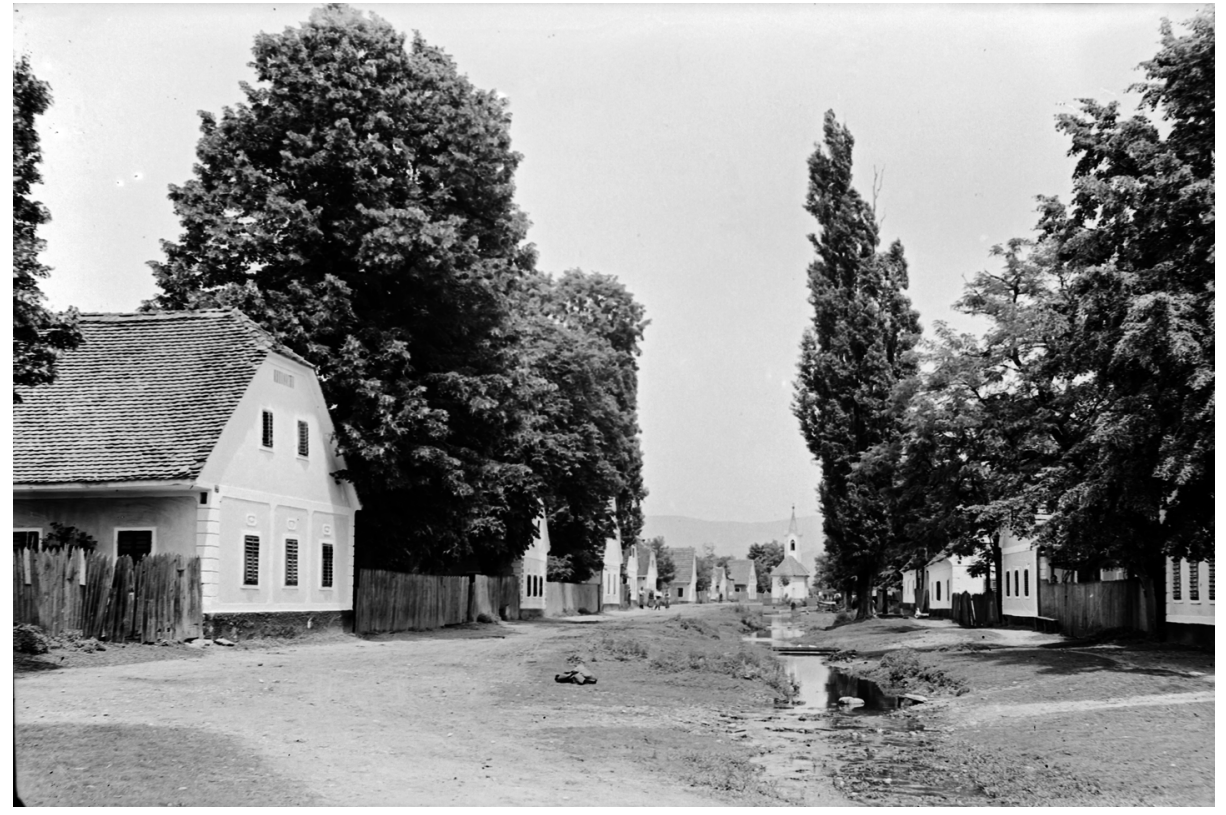

Slovenske gorice: pogled od Kapele proti severozahodu.

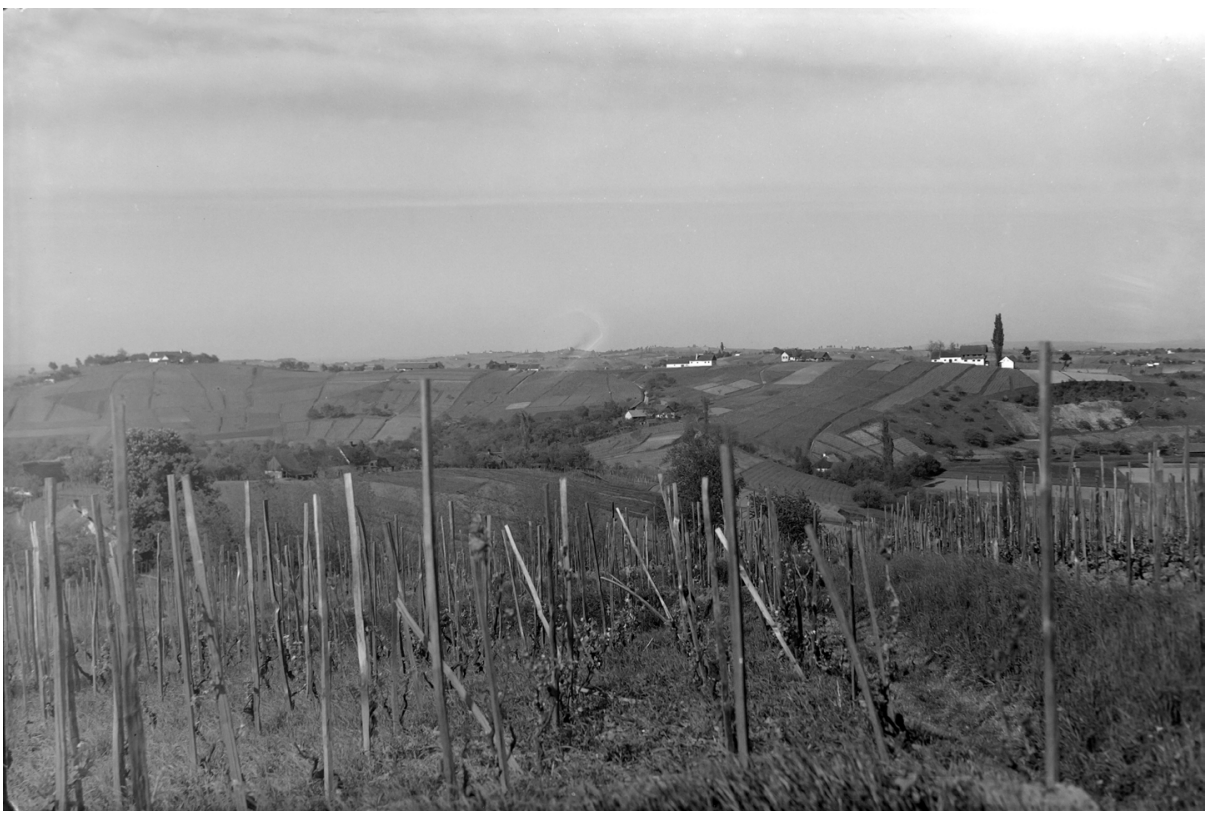


Vas Želuče v Rožu.

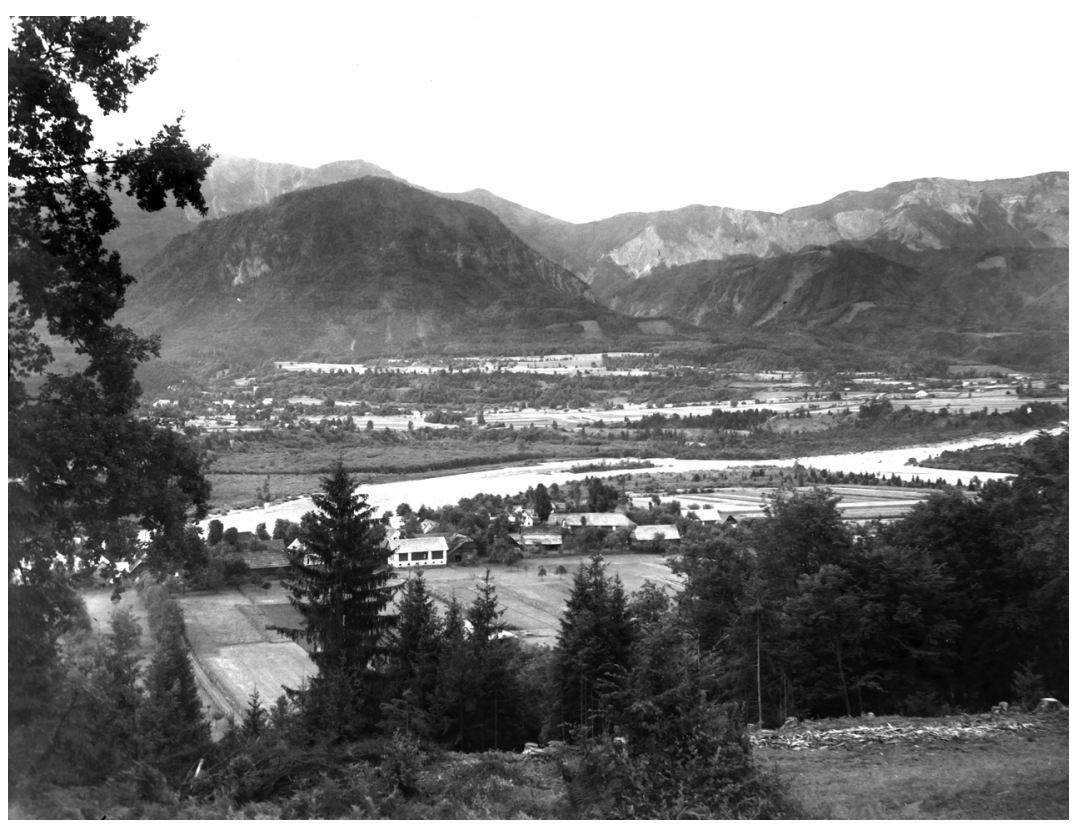

Planina Javornik na Pokljuki.

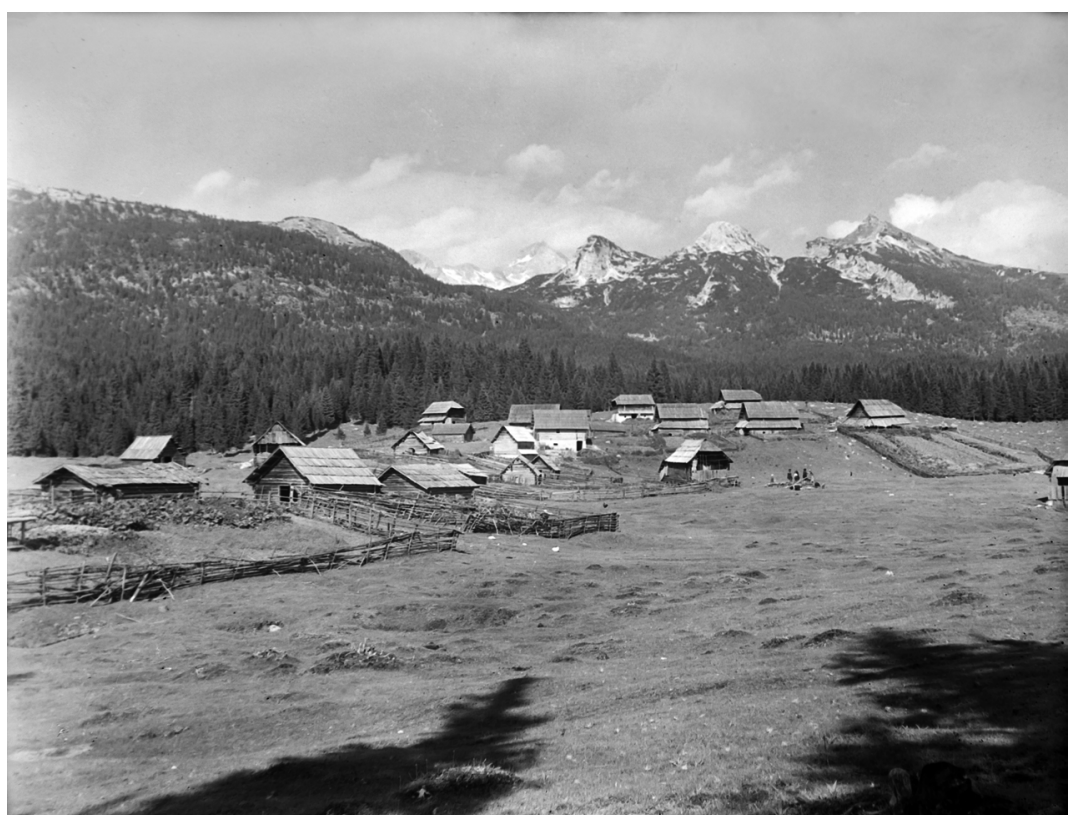

